\title{
Normal Konsolide Kaolin Kilinin Drenajsız Kesme Davranışı Üzerinde Başlangıç Kayma Gerilmesinin Etkisi
}

\author{
Geliş / Received: 02/02/2020
}

\author{
Uğur Dağdeviren ${ }^{1 *}$, Zeki Gündüz ${ }^{2}$
}

Revize / Revised: 13/06/2020

Kabul / Accepted: 22/06/2020

\section{ÖZ}

Arazideki zeminlerin gerilme koşulları incelendiğinde, zeminlerin pek çok durumda anizotropik gerilme şartlarında olduğu görülmektedir. Bu zeminler, herhangi bir ilave yükleme olmasa dahi kayma gerilmesine maruz durumdadırlar. Günümüzde arazideki gerilme şartlarına bakılmaksızın, maliyet, zaman ve kolaylık gibi gerekçelerden dolayı üç eksenli basınç deneyleri izotropik gerilmeler altında ve başlangıç kayma gerilmesinin olmadığı numuneler üzerinde gerçekleştirilmektedir. Bu nedenle, zeminlerin drenajsı koşullardaki davranışı üzerinde başlangıç kayma gerilmesi varlığının etkisi belirlenmesi gereken önemli bir konudur. Bu çalışmada, laboratuvarda bulamaç çamuru konsolidasyon yöntemi ile hazırlanmış olan normal konsolide kaolin kilinin, farklı başlangıç kayma gerilmeleri ve ortalama efektif gerilmeler altındaki drenajsız davranışı üç eksenli basınç deneyleri kullanılarak incelenmiştir. Deney sonuçları, başlangıç kayma gerilmesindeki artışın, drenajsız kayma mukavemetini ve aşırı boşluk suyu basıncı oluşumunu önemli ölçüde etkileyebileceğini göstermektedir. Çalışma sonunda, izotropik koşullarda gerçekleştirilen üç eksenli basınç deneylerinden elde edilen drenajsız kayma mukavemeti kullanılarak, başlangıç kayma gerilmesine maruz kil zeminlerin drenajsız kayma mukavemetini belirlemeye yönelik olarak bir düzeltme faktörü önerilmiştir.

Anahtar Kelimeler- Başlangıç Kayma Gerilmesi, Boşluk Suyu Basıncı, Drenajsız Kayma Mukavemeti, Düzeltme Faktörü, Üç Eksenli Basinç Deneyi.

\footnotetext{
1*Sorumlu yazar iletişim: ugur.dagdeviren@dpu.edu.tr (https://orcid.org/0000-0002-4760-6574) Inşaat Mühendisliği Bölümü, Kütahya Dumlupınar Üniversitesi, 43100, Kütahya

2İletişim: zekigunduz@aydin.edu.tr (https://orcid.org/0000-0002-5284-7532)

İnşaat Mühendisliği Bölümü, İstanbul Aydın Üniversitesi, 34295, İstanbul
} 


\title{
Effect of Initial Shear Stress on the Undrained Shear Behavior of Normally Consolidated Kaolin Clay
}

\begin{abstract}
When the stress conditions of the soils in the field are examined, it is seen that the soils are in the anisotropic stress conditions in many cases. These soils are subjected to shear stress even without additional loading. Today, regardless of the stress conditions in the field, triaxial compression tests are carried out on samples without initial shear stress under the isotropic stress conditions because of the cost, time and simplicity. Therefore, determining the effect of the presence of the initial shear stress on the behavior of soils under the undrained conditions is an important subject. In this study, the undrained behavior of the normally consolidated kaolin clay, which is prepared by slurry consolidation method in the laboratory, under different initial shear stresses and mean effective stresses is investigated using the triaxial compression tests. The test results show that the increase in initial shear stress can significantly affect the undrained shear strength and the generation of excess pore water pressure. At the end of the study, a correction factor is proposed that can be used to determine the undrained shear strength of clay soils subjected to initial shear stresses by using the undrained shear strength obtained from the triaxial compression tests performed in isotropic conditions.
\end{abstract}

Keywords- Initial Shear Stress, Pore Water Pressure, Undrained Shear Strength, Correction Factor, Triaxial Compression Test. 


\section{GíRiş}

Geoteknik mühendisliği uygulamalarında, üzerinde ilave bir yükleme olmasa dahi, sükûnetteki $\left(\mathrm{K}_{0}\right)$ arazi koşullarındaki zemin elemanlarının genellikle anizotropik gerilme şartlarında olduğu görülmektedir. Benzer şekilde, yapıların simetri ekseni dışındaki noktalarda veya dolgular, şevler ve toprak dolgu barajlar gibi eğimli yüzeylerde yer alan zemin elemanlarının da serbest saha koşullarından farklı olarak anizotropik gerilme şartlarında olduğu bilinmektedir [1-4]. Bu zemin elemanları herhangi bir ilave gerilme öncesinde de kayma gerilmelerine maruz durumdadırlar. Özellikle drenajsız şartlar altında, kumlu zeminlerin tekrarlı yükler altındaki davranışları üzerinde başlangıç statik kayma gerilmesinin etkileri sıvılaşma direnci açısından oldukça önemli bir konu olup günümüzde halen birçok araştırmacı tarafından ele alınmaktadır [2, 4-6]. Bu çalışmalar, başlangıç statik kayma gerilmesi varlığının, doygun kumların dinamik özelliklerini etkileyen önemli bir faktör olduğunu ortaya koymakta ve bu etkiyi yansıtabilmek için düzeltme faktörleri $\left(\mathrm{K}_{\alpha}\right)$ önermektedirler. Killi zeminler üzerinde başlangıç statik kayma gerilmesinin etkilerini ele alan çalışmalar ise daha sınırlı olup, bunların çoğu da tekrarlı yükler altındaki davranış üzerine yoğunlaşmıştır [3, 7-9]. Killi zeminler üzerinde başlangıç kayma gerilmesinin etkilerini ele alan deneysel bulguları zenginleştirebilmek ve davranışı doğru olarak yorumlayabilmek için bu konu hakkındaki çalışmaların da artırılması gerektiği gözlenmektedir.

Öte yandan, arazideki zeminlerin maruz kalacakları gerilmeler altındaki davranışlarını belirleyebilmek için yapılan laboratuvar deneylerinin, esasen arazideki gerilme koşullarına uygun olarak hazırlanmış örselenmemiş numuneler üzerinde gerçekleştirilmesi gerekmektedir. Ancak, günümüzde laboratuvar üç eksenli basınç deneyleri, arazideki gerilme koşullarına bakılmaksızın izotropik gerilme koşulları altındaki numuneler üzerinde gerçekleştirilmektedir. Üç eksenli basınç deney sisteminde uygulanan izotropik gerilme şartlarının, başlangıç kayma gerilmesine maruz zeminlerin arazideki davranışlarını ne ölçüde yansıtabileceği merak konusudur. Özellikle normal konsolide killer için, izotropik şartlarda gerçekleştirilen deneylerden elde edilen drenajsız kayma mukavemetinin, genellikle anizotropik şartlardakinden daha büyük olduğuna yönelik gözlemler de $[10,11]$ dikkate alındığında; izotropik şartlardaki deneylerden elde edilen kayma direnci davranışının direkt olarak arazide farklı gerilme koşullarına sahip zeminler için kullanımı, gerçek kayma direnci değerlerinden daha yüksek değerlerle değerlendirme yapılmasına ve tasarımın emniyetsiz tarafta kalma riskine neden olabilecektir. Bu nedenle, killi zeminlerin davranışı üzerinde başlangıç kayma gerilmesinin etkisi irdelenmesi gereken bir konu olarak değerlendirilmiş̧ir.

Bu çalışmada, monotonik yükleme altında killi zeminlerin drenajsız koşullardaki davranışı üzerinde başlangıç kayma gerilmesi seviyesinin etkilerinin belirlenmesi hedeflenmiştir. Bu amaç doğrultusunda, iki farklı ortalama efektif gerilme seviyesi için normal konsolide kaolin kili kullanılarak başlangıç kayma gerilmesinin etkisi incelenmiştir. Çalışmada kullanılan numunelerin heterojenlik, gerilme geçmişi, su muhtevası, başlangıç boşluk oranı gibi parametrelerin farklılıklarını devre dışı bırakabilmek için, laboratuvar ortamında bulamaç çamuru konsolidasyon yöntemi ile numuneler hazırlanmış ve sadece başlangıç kayma gerilmesinin değişkenliği sağlanmaya çalışılmışıtır. Numuneler, üç eksenli basınç deneyinde, izotropik ve başlangıç kayma gerilmesinin modellendiği deneylerde ise izotropik konsolidasyonu takiben drenajlı ön-kesme altında konsolide edilmiş ve daha sonra drenajsız kesme aşamasındaki davranışları gerilme-deformasyon, aşırı boşluk suyu basıncı oluşumu ve gerilme izi açısından incelenmiştir. Sonuçlar, normal konsolide kaolin kili üzerinde başlangıç kayma gerilmesi varlığının, gerek kayma mukavemeti gerekse boşluk suyu basıncı oluşumu açısından ihmal edilemeyecek öneme sahip olabileceğini göstermiştir. Çalışma sonuçlarına dayalı olarak, monotonik yükleme için üç eksenli basınç deneylerinde izotropik gerilme koşulları altında belirlenmiş olan kayma direnci değerlerinden, başlangıç kayma gerilmesine maruz zeminlerin kayma direnci değerlerine geçiş yapmayı sağlayabilecek yeni bir düzeltme faktörü $\left(\mathrm{K}_{\mathrm{s}}\right)$ önerilmiştir.

Çalışmanın kalan bölümleri aşağıdaki gibi düzenlenmiştir: Deneylerde kullanılan zemin özellikleri, numunelerin hazırlanma yöntemi ile deney sistemi ve deney programı Bölüm 2'de tanımlanmaktadır. Deney sonuçları Bölüm 3'de, bulguların değerlendirilmesi ve tartışılması ise Bölüm 4'de sunulmuştur. Çalışmanın son bölümünde ise elde edilen önemli sonuçlar ortaya konulmuştur. 


\begin{tabular}{|c|c|c|}
\hline & $\begin{array}{l}\text { BŞEÜ Fen Bilimleri Dergisi } \\
7(1), 484-496,2020\end{array}$ & $\begin{array}{r}\text { BSEU Journal of Science } \\
\text { DOI: } 10.35193 / \text { bseufbd.683455 }\end{array}$ \\
\hline IERSI & & 58-7575 (http://dergipark.gov.tr/bseufbd) \\
\hline
\end{tabular}

\section{MALZEME VE YÖNTEM}

\section{A. Zemin Özellikleri ve Numune Hazırlama Yöntemi}

Çalışma kapsamında gerçekleştirilen deneylerde, arazideki doğal zeminlerin yapı, heterojenlik, gerilme geçmişi, su muhtevası, boşluk oranı farklılıkları gibi zemin davranışı üzerinde önemli etkiye sahip olan parametrelerin etkisini devre dışı bırakabilmek için, numunelerinin laboratuvarda hazırlanması tercih edilmiştir. Bu amaçla, deneylerde önemli kil türlerinden birisi olan ve geoteknik özellikleri Tablo 1'de verilen kaolin kili kullanılmıştır.

Kullanılan numunelerin homojen ve yüksek doygunlukta olması, ve başlangıç boşluk oranlarının dar bir aralıkta kalması hedeflendiğinden, numuneler bulamaç çamuru konsolidasyon yöntemi ile hazırlanmıştır [12-16]. Bu yöntemde, etüv kurusu haline getirilmiş olan kaolin kilinin bulamaç hale gelmesi için, likit limitin üzerinde bir su muhtevasında $\left(\mathrm{w}_{\mathrm{n}}=\%\right.$ 65) karıştırıldıktan sonra, nemin dengelenmesi için sıcaklığı $20 \pm 3{ }^{\circ} \mathrm{C}$, bağıl nemi ise $\% 95$ olan nem odasında en az bir gün boyunca bekletilmiştir. Hazırlanan bulamaç, aralarda boşluk kalmaması için hafif bir titreşim uygulanarak, alt ve üst yüzeyleri drenaja açık olan $20 \mathrm{~cm}$ kenar uzunluklu küp şeklindeki büyük konsolidasyon tankına yerleştirilmiştir. Numune tankının üst başlığından pnomatik silindir ile eksenel yükleme uygulanarak numunenin önkonsolidasyonu sağlanmıştır (Şekil 1.a). Deney sisteminde kullanılan ekipmanların kapasiteleri itibariyle emniyetli olarak uygulanabilecek en büyük gerilme seviyesine (62.5 kPa), taşıma gücü probleminin oluşmaması için 15, 30, 45 ve $62.5 \mathrm{kPa}$ olmak üzere 4 yükleme kademesinde erişilmiştir. Her yükleme kademesinde oturmaların tamamlanabilmesi için 1 hafta beklenmiştir. Bir aylık önkonsolidasyon sürecinin ardından, ince cidarlı numune alıcıların hidrolik pistonla konsolidasyon tankı içerisindeki zemine itilmesi ile (Şekil 1.b) üç eksenli basınç deneylerinde kullanılacak olan $35.7 \mathrm{~mm}$ çapında ve $80 \mathrm{~mm}$ yüksekliğinde silindirik zemin numuneleri elde edilmiştir. Bu yöntem ile elde edilen numunelerin başlangıç boşluk oranlarının, $\mathrm{e}_{0}=1.25 \pm 0.02$, doğal birim hacim ağırlıklarının, $\gamma_{\mathrm{n}}=16.61 \pm 0.11 \mathrm{kN} / \mathrm{m}^{3}$ ve sıvılık indislerinin, $\mathrm{I}_{\mathrm{L}}=0.75 \pm 0.03$ gibi çok dar bir aralık içerisinde kaldığı gözlenmiştir.

Tablo 1. Çalıșmada kullanılan kaolin kilinin indeks özellikleri

\begin{tabular}{cccccccc}
\hline $\begin{array}{c}\text { Likit limit, } \\
\text { LL }(\%)\end{array}$ & $\begin{array}{c}\text { Plastik } \\
\text { limit, } \\
\text { PL }(\%)\end{array}$ & $\begin{array}{c}\text { Plastisite } \\
\text { indisi, } \\
\text { PI }(\%)\end{array}$ & $\begin{array}{c}\text { Özgül } \\
\text { gravite, } \mathrm{G}_{\mathrm{s}}\end{array}$ & $\begin{array}{c}\text { Kum } \\
\text { yüzdesi } \\
(\%)\end{array}$ & $\begin{array}{c}\text { Silt } \\
\text { yüzdesi } \\
(\%)\end{array}$ & $\begin{array}{c}\text { Kil } \\
\text { yüzdesi } \\
(\%)\end{array}$ & $\begin{array}{c}\text { USCS } \\
\text { snnffi }^{*}\end{array}$ \\
\hline * & 34 & 17 & 2.59 & 0 & 49 & 51 & MH \\
\hline USCS: Birleştirimiș zemin snnflandırma sistemi & & & & &
\end{tabular}
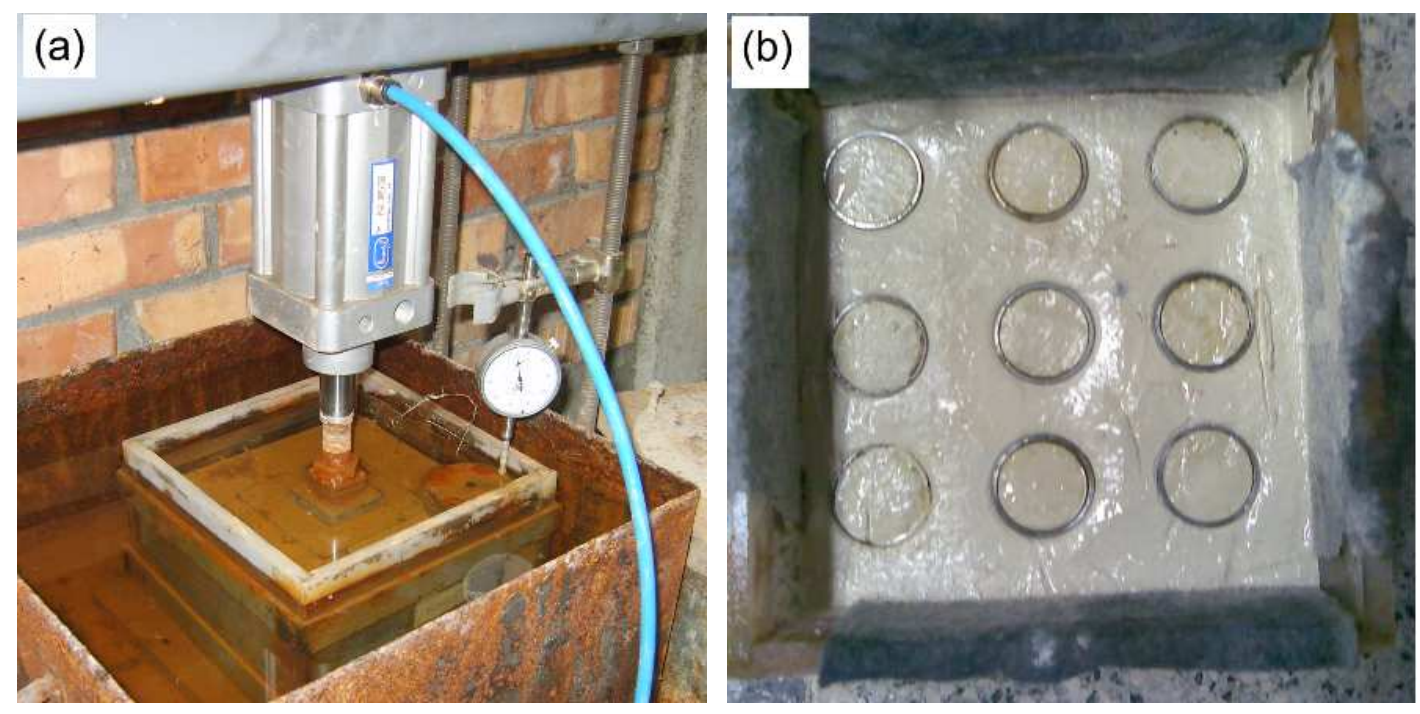

Şekil 1. Numune hazırlama sistemi, a) Yükleme düzeneği, b) Numune alımı 


\section{B. Deney Prosedürü ve Deney Programı}

Çalışmada tam otomatik üç eksenli deney sistemi kullanılmıştır. Deney numunelerinin konsolidasyonun hızlandırılması ve boşluk suyu basıncının homojen dağılımının sağlanabilmesi için numunelerin etrafı filtre kağıdı ile sarılmıştır. Numunelerin doyurma aşaması; 16 kademede 30 kPa'lık basınç artışları ile $490 \mathrm{kPa}$ 'lık bir geri basınca erişilerek tamamlanmış ve boşluk suyu basıncı parametresi (B) değerinin en az 0.95 olması sağlanmıştır. Doyurma işleminden sonra, başlangıç kayma gerilmesi seviyesinden bağımsız olarak deneylerde kullanılan tüm numunelerde öncelikle hedeflenen izotropik efektif konsolidasyon gerilme seviyesine ulaşılarak 24 saatten az olmamak üzere numunelerin birincil konsolidasyonunu tamamlamasına izin verilmiş ve bu aşamada hacim değişimleri ölçülmüştür. Başlangıç kayma gerilmesi varlığının modellenmek istendiği numunelerde ise, izotropik gerilme koşulları altındaki konsolidasyonun akabinde, hücre basıncı sabit tutularak, düşey deviatör gerilme, yükleme hızına yönelik olarak bir standart bulunmadığ için literatürdeki uygulamalarla uyumlu olacak şekilde, 1 $\mathrm{kPa} /$ min yükleme hızıyla artırılmış ve numuneye drenajlı şartlarda ön bir kesme işlemi uygulanmıştır [1, 17-18]. Hedeflenen başlangıç kayma gerilmesinin sağlanmasının ardından, 24 saatlik ikinci bir konsolidasyon süreci uygulanmış ve zemin numunelerinin anizotropik gerilme koşullarına gelmesi sağlanmıştır.

İzotropik ve/veya anizotropik konsolidasyon aşamaları tamamlandıktan sonra, drenajsız üç eksenli basınç deneyleri (CIU/CAU) birim deformasyon kontrollü olarak gerçekleştirilmiştir. Drenajsız kesme sırasında boşluk suyu basıncının numune boyunca homojen dağılımını sağlayabilmek için birim şekil değiştirme hızı, ASTM D4767'de tanımlanan en büyük yükleme hızını aşmayacak şekilde, $0.014 \%$ /min olarak seçilmiştir [19-23]. Kesme aşamasında, yük hücresi okuması, eksenel deformasyon ve aşırı boşluk suyu basıncı değerleri bilgisayar kontrollü olarak kaydedilmiştir. Gerçekleştirilen deneylerde zemin numunelerinin gerilme-birim deformasyon grafiklerinde net olarak pik noktaları gözlendiğinden dolayı, yenilme anı, deviatör gerilmenin maksimum değere ulaştığı birim deformasyon seviyesi olarak tanımlanmıştır [23].

Killi zeminlerin drenajsız yükleme koşulları altındaki davranışının; zeminin plastisitesi, gerilme geçmişi, doygunluk derecesi, başlangıç su muhtevası, başlangıç boşluk oranı ve yükleme hızı gibi birçok faktörden etkilendiği bilinmektedir. Bu nedenle, çalışmada sadece başlangıç kayma gerilmesi seviyesinin zemin davranışı üzerindeki etkisini ortaya koyabilmek için, diğer tüm parametrelerin sabit tutulduğu bir deney programının oluşturulması hedeflenmiştir. Bu aşamada, drenajsız kesme öncesi başka bir deyişle izotropik/anizotropik konsolidasyon sonrası boşluk oranının $\left(\mathrm{e}_{\mathrm{c}}\right)$ sabitliğinin sağlanması, konsolidasyon sırasında numunede oluşacak hacim ve boşluk oranı değişimini önceden kestirebilmek mümkün olmadığından diğer parametrelere nazaran daha zordur. Bu çalışmada, farklı gerilme izlerine sahip olarak hazırlanacak olan numunelerin konsolidasyon sonrası boşluk oranını $\left(\mathrm{e}_{\mathrm{c}}\right)$ birbirlerine mümkün olduğunca yakın tutabilmek için sabit ortalama efektif gerilmeye, $\mathrm{p}^{\prime}=$ $\left(\sigma_{1}+\sigma_{2}+\sigma_{3}\right) / 3$ sahip numunelerin oluşturulmasını esas alan sistematik bir deney programı ele alınmıştır. Bu deney programının ilk grubundaki numuneler (Grup I), izotropik olarak konsolide edilmiş ve drenajsız kesme öncesinde başlangıç kayma gerilmesinin oluşmadığı $\left(\tau_{\mathrm{s}}=0\right)$ numunelerdir. Tablo 2 'de görüleceği üzere, bu numuneler 100 , 200 ve $400 \mathrm{kPa}$ 'lık izotropik efektif çevre gerilmeleri altında konsolide edilmişlerdir. İkinci gruptaki deney numuneleri (Grup II) ise, öncelikle izotropik çevre gerilmesi altında konsolide edilmiş, daha sonra istenilen başlangıç kayma gerilmesine ulaşmak üzere drenajlı şartlarda eksenel deviatör gerilmeye maruz bırakılmışlardır $[2,5,7,24-26]$. Bu gruptaki deneyler, Tablo 2'de özetlendiği üzere, ortalama efektif gerilmenin p' $=200 \mathrm{kPa}$ (Grup II-a) ve p' $=400 \mathrm{kPa}$ (Grup II-b) olduğu yedi adet numuneden oluşmaktadır. Bu deneyler için başlangıç kayma gerilmesi oranları, $\tau_{s} / p^{\prime}=0.15,0.30,0.45$ ve 0.60 olarak seçilmiştir. Sabit ortalama efektif gerilmeli $\left(p^{\prime}\right)$ ve hedeflenen başlangıç kayma gerilmesine sahip zemin numunelerini elde edebilmek için uygulanması gereken efektif çevre gerilmesi $\left(\sigma_{3 c}{ }^{\prime}\right)$ ve düşey efektif gerilme $\left(\sigma_{1 c}{ }^{\prime}\right)$ değerleri, zeminlerin davranışında etkin olduğu bilinen ortanca efektif asal gerilme etkisinin de gerilme izinde dikkate alındığı Cambridge gerilme izi ifadelerine dayalı olarak Denklem 1 ve 2'deki gibi formüle edilebilir.

$$
\begin{aligned}
& \sigma_{3 c}{ }^{\prime}=p^{\prime}-\frac{2}{3} \tau_{s} \\
& \sigma_{1 c}{ }^{\prime}=p^{\prime}+\frac{4}{3} \tau_{s}
\end{aligned}
$$




\begin{tabular}{|c|c|c|}
\hline & $\begin{array}{l}\text { BŞEÜ Fen Bilimleri Dergisi } \\
7(1), 484-496,2020\end{array}$ & $\begin{array}{r}\text { BSEU Journal of Science } \\
\text { DOI: } 10.35193 / \text { bseufbd. } 683455\end{array}$ \\
\hline & & $8-7575$ (http://dergipark.gov.tr/bseufbd) \\
\hline
\end{tabular}

Tablo 2. Uygulanan deney programı

\begin{tabular}{cccccccc}
\hline $\begin{array}{c}\text { Deney } \\
\text { Grup No. }\end{array}$ & $\begin{array}{c}\text { Numune } \\
\text { No. }\end{array}$ & $\begin{array}{c}\sigma_{3 c^{\prime}} \\
(\mathrm{kPa})\end{array}$ & $\begin{array}{c}\sigma_{1 \mathrm{c}^{\prime}} \\
(\mathrm{kPa})\end{array}$ & $\mathrm{p}^{\prime}(\mathrm{kPa})$ & $\tau_{\mathrm{s}}(\mathrm{kPa})$ & $\tau_{\mathrm{s}} / \mathrm{p}^{\prime}$ & $\mathrm{e}_{\mathrm{c}}$ \\
\hline \multirow{3}{*}{ Grup I } & CIU-01 & 100 & 100 & 100 & 0 & 0 & 1.09 \\
& CIU-02 & 200 & 200 & 200 & 0 & 0 & 1.06 \\
& CIU-03 & 400 & 400 & 400 & 0 & 0 & 1.01 \\
\hline \multirow{5}{*}{ Grup II-a } & CAU-01 & 180 & 240 & 200 & 30 & 0.15 & 1.06 \\
& CAU-02 & 160 & 280 & 200 & 60 & 0.30 & 1.05 \\
& CAU-03 & 140 & 320 & 200 & 90 & 0.45 & 1.08 \\
& CAU-04 & 120 & 360 & 200 & 120 & 0.60 & 1.05 \\
\hline \multirow{3}{*}{ Grup II-b } & CAU-05 & 360 & 480 & 400 & 60 & 0.15 & 0.99 \\
& CAU-06 & 320 & 560 & 400 & 120 & 0.30 & 0.98 \\
& CAU-07 & 280 & 640 & 400 & 180 & 0.45 & 0.97 \\
\hline
\end{tabular}

\section{DENEY SONUÇLARI}

Çalışmada uygulanan deney programı için, her iki gruptaki deney numunelerinin drenajsız kesme öncesi izotropik ve anizotropik konsolidasyon sırasındaki gerilme izleri Şekil 2'de gösterilmiştir. Tablo 2'den bu numunelerin, izotropik veya anizotropik konsolidasyon sonundaki boşluk oranları incelendiğinde, $\mathrm{p}^{\prime}=200 \mathrm{kPa} \mathrm{\prime}^{\prime} \mathrm{lk}$ gerilme altındaki numunelerin boşluk oranlarının, $\mathrm{e}_{\mathrm{c}}=1.05 \sim 1.08$ aralığında; $\mathrm{p}^{\prime}=400 \mathrm{kPa}$ olan numuneler için ise, $\mathrm{e}_{\mathrm{c}}=0.97 \sim 1.01$ gibi oldukça dar bir aralık içerisinde kaldığı gözlenmiştir. Bu nedenle, yapılan değerlendirmelerde, aynı ortalama efektif gerilmeye maruz numunelerin arasındaki tek farklılığın, drenajsız kesme aşaması öncesindeki başlangıç kayma gerilmesi seviyeleri olduğu rahatlıkla söylenebilecektir.

100, 200 ve $400 \mathrm{kPa}$ 'lık efektif çevre gerilmeleri altında izotropik olarak konsolide edilen numuneler üzerinde gerçekleştirilen konsolidasyonlu drenajsız üç eksenli basınç deneyleri (CIU) için gerilme izleri ve yenilme zarfı Şekil 2'de gösterilmektedir. Normal konsolide edilen Grup I'deki (CIU) numunelerin gerilme izleri incelendiğinde, drenajsız kesme sırasında numunelerin sıkışma eğilimi göstermesi sonucunda boşluk suyu basınçlarında artış gerçekleştiği görülmektedir. Drenajlı şartlarda ön-kesmeye maruz bırakılan numunelerin ise gerilme izi eğiminin $3 / 1$ oranında artarak hedeflenen gerilme durumlarına ulaştıkları gözlenmektedir. Ayrıca, Tablo 2'de verilen deney programındaki CAU-04 no.lu numunenin drenajlı koşullar altında başlangıç kayma gerilmesine maruz bırakılması aşamasında, gerilme izinin 3/1 eğimle ilerlemesi sonucunda hedeflenen gerilme seviyesine ulaşamadan yenilme zarfına ulaştığı için bu numunede yenilme gerçekleşmiş ve deney sonlandırılmıştır. Bu nedenle, drenajsız kesme aşamasındaki zemin numunelerinin davranışlarının ele alındığı aşağıdaki değerlendirmelerde bu numuneye ait bir değerlendirme yapılamayacaktır.

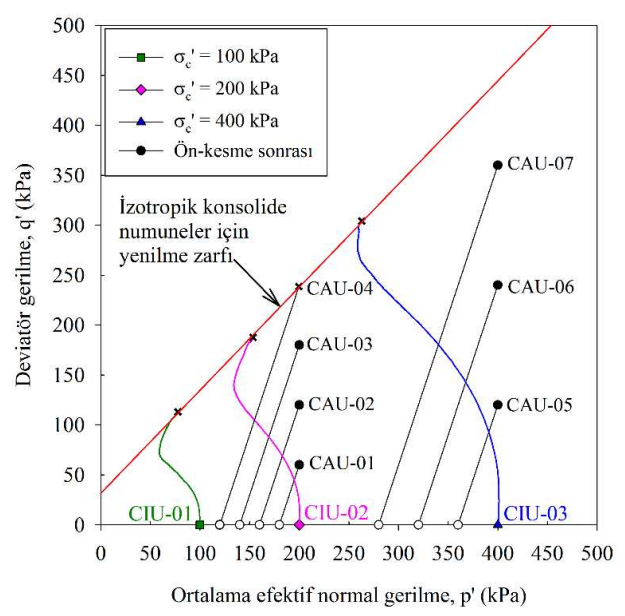

Şekil 2. İzotropik ve kesme öncesi anizotropik yüklenen numuneler için gerilme izleri 


\begin{tabular}{|c|c|c|}
\hline & $\begin{array}{l}\text { BŞEÜ Fen Bilimleri Dergisi } \\
7(1), 484-496,2020\end{array}$ & $\begin{array}{r}\text { BSEU Journal of Science } \\
\text { DOI: } 10.35193 / \text { bseufbd. } 683455\end{array}$ \\
\hline & & $8-7575$ (http://dergipark.gov.tr/bseufbd) \\
\hline
\end{tabular}

Başlangıç kayma gerilmesi seviyesinin etkisini ortaya koymak için hazırlanan Grup II-a (p' = $200 \mathrm{kPa}$ ) ve Grup II-b ( $\mathrm{p}^{\prime}=400 \mathrm{kPa}$ )'deki numuneler için drenajsız kesme aşamasındaki deviatör gerilme ve aşırı boşluk suyu basıncının eksenel birim deformasyonla değişimleri ve gerilme izleri aşağıdaki alt bölümlerde ayrı ayrı ele alınmıştır. Numunelerin yenilme sonrası davranışını gözlemleyebilmek için, gerilme birim deformasyon eğrisinde pik noktaya eriştikten sonra bir süre daha yüklemeye devam edilmiştir.

\section{A. Gerilme - Eksenel Birim Deformasyon Davranışı}

Şekil 3'de ortalama efektif gerilmesi p' $=200$ ve $400 \mathrm{kPa}$ olan numunelerin deviatör gerilme - birim deformasyon grafikleri verilmiştir. Gerek izotropik gerekse anizotropik olarak konsolide edilen numuneler, pik deviatör gerilme değerine ulaştıktan sonra birim deformasyon yumuşaması davranışı göstermektedir. Şekil 3.a'da başlangıç kayma gerilmesinin olmadı̆̆ 1 durum için $\left(\tau_{s} / \mathrm{p}^{\prime}=0\right)$ yenilme $188 \mathrm{kPa} \mathrm{a}^{\prime} \mathrm{l} \mathrm{k}$ bir deviatör gerilmede gerçekleşmişken, aynı ortalama efektif gerilme seviyesi için $\tau_{s} / p^{\prime}$ değerinin $0.15,0.30$ ve 0.45 olduğu numunelerde maksimum deviatör gerilmenin $\left(\sigma_{\mathrm{d}, \max }\right)$ sirasıyla yaklaşık $130 \mathrm{kPa}, 113 \mathrm{kPa}$ ve $74 \mathrm{kPa}$ olduğu gözlenmiş̧tir. Benzer şekilde, Şekil 3.b'de p' = $400 \mathrm{kPa}$ olan numuneler içindeki maksimum deviatör gerilme değerleri başlangıç kayma gerilmesinin artışı ile $304 \mathrm{kPa}$ 'dan sırasıyla $227 \mathrm{kPa}, 172 \mathrm{kPa}$ ve $83 \mathrm{kPa}$ seviyelerine kadar düşmektedir. Başlangıç kayma gerilmesinin artışıla, maksimum deviatör gerilmede gözlemlenen bu azalımlar $\tau_{s} / \mathrm{p}^{\prime}=0.15$ olan numunelerde $\% 25-31$ aralığında, $\tau_{s} / \mathrm{p}^{\prime}=0.30$ olan numunelerde $\% 40-43$ aralığında, $\tau_{s} / \mathrm{p}^{\prime}=0.45$ olan numunelerde ise \%60-73 aralığındadır. Bu değerler göz önüne alındığında, başlangıç kayma gerilmesi varlığının zeminlerin kayma direnci üzerinde ihmal edilemeyecek kadar önemli olduğu açıkça görülmektedir. Şekil 3'deki başlangıç kayma gerilmesi oranları ve ortalama efektif gerilme koşullarındaki tüm numuneler için yenilme anındaki maksimum deviatör gerilmenin yarısı $\left(\sigma_{\mathrm{d}, \max } / 2\right)$ olarak tanımlanan drenajsız kayma mukavemeti $\left(\mathrm{s}_{\mathrm{u}}\right)$ değerleri Tablo 3'de özetlenmiştir.
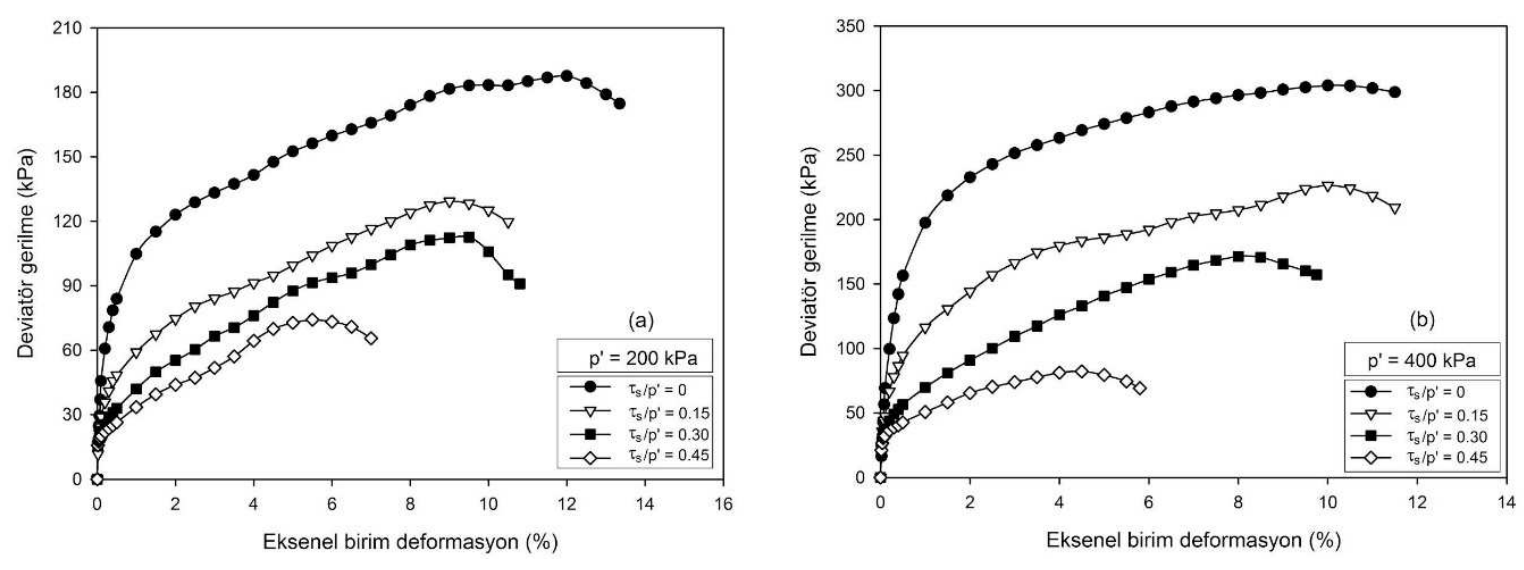

Şekil 3. a) p' = $200 \mathrm{kPa}$, b) p' = $400 \mathrm{kPa}$ için drenajsız kesme aşamasında deviatör gerilme - birim deformasyon davranışı

Tablo 3. Drenajsız kayma mukavemetleri ve yenilme anındaki aşırı boşluk suyu basınçları

\begin{tabular}{cccccc}
\hline Numune No. & $\begin{array}{c}\mathrm{p}^{\prime} \\
(\mathrm{kPa})\end{array}$ & $\begin{array}{c}\tau_{\mathrm{s}} \\
(\mathrm{kPa})\end{array}$ & $\tau_{\mathrm{s}} / \mathrm{p}^{\prime}$ & $\begin{array}{c}\mathrm{s}_{\mathrm{u}}\left(\sigma_{\mathrm{d}, \max } / 2\right) \\
(\mathrm{kPa})\end{array}$ & $\begin{array}{c}\Delta \mathrm{u}_{\mathrm{f}} \\
(\mathrm{kPa})\end{array}$ \\
\hline CIU-02 & 200 & 0 & 0 & 93.9 & 109.0 \\
CAU-01 & 200 & 30 & 0.15 & 64.8 & 91.1 \\
CAU-02 & 200 & 60 & 0.30 & 56.6 & 48.2 \\
CAU-03 & 200 & 90 & 0.45 & 37.2 & 21.4 \\
CAU-04 & 200 & 120 & 0.60 & - & - \\
\hline CIU-03 & 400 & 0 & 0 & 152.0 & 238.3 \\
CAU-05 & 400 & 60 & 0.15 & 113.4 & 191.8 \\
CAU-06 & 400 & 120 & 0.30 & 86.1 & 91.0 \\
CAU-07 & 400 & 180 & 0.45 & 41.3 & 35.8 \\
\hline
\end{tabular}




\begin{tabular}{|c|c|c|}
\hline & $\begin{array}{l}\text { BŞEÜ Fen Bilimleri Dergisi } \\
7(1), 484-496,2020\end{array}$ & $\begin{array}{r}\text { BSEU Journal of Science } \\
\text { DOI: } 10.35193 / \text { bseufbd. } 683455\end{array}$ \\
\hline & & $8-7575$ (http://dergipark.gov.tr/bseufbd) \\
\hline
\end{tabular}

Şekil 3'de verilen numunelerin deviatör gerilme birim deformasyon grafikleri incelendiğinde gözlenen bir diğer nokta ise, başlangıç kayma gerilmesi oranlarının artışı ile zemin numunelerinin daha düşük deformasyon seviyelerinde yeniliyor olmasıdır. Örneğin, Şekil 3.a'da başlangıç kayma gerilmesinin olmadığ durum için $\left(\tau_{\varsigma} / \mathrm{p}^{\prime}\right.$ $=0$ ) yenilme yaklaşık $\% 12$ eksenel birim deformasyon seviyesinde gerçekleşmişken, $\tau_{s} / \mathrm{p}^{\prime}=0.45$ olan numunenin yenilme anındaki eksenel birim deformasyonu $\% 5.5$ olarak gözlenmiştir. Şekil 3.b'deki $\mathrm{p}^{\prime}=400 \mathrm{kPa}$ olan numunelerin yenilme anındaki birim deformasyonları ise $\tau_{s} / \mathrm{p}^{\prime}=0$ 'dan $0.45^{\prime} \mathrm{e}$ kadar olan numunelerde sırasıyla, \%10.4, 10.0, 8.2 ve 4.3 olarak belirlenmiştir. Bu durum, başlangıç kayma gerilmesine maruz olan zeminlerde yenilmelerin daha hızlı ve düşük deformasyon seviyelerinde gerçekleşeceğini göstermektedir.

\section{B. Aşııı Boşluk Suyu Basıncı Davranışı}

Çalışmada gerçekleştirilen deneylerde, zemin numunelerinde drenajsız kesme sırasında oluşan aşırı boşluk suyu basıncının birim deformasyonla değişimi Şekil 4'de sunulmuş, Tablo 3'de ise yenilme anındaki aşırı boşluk suyu basıncı değerleri ayrıca özetlenmiştir. Tüm gerilme koşullarındaki numuneler için, boşluk suyu basıncının en büyük değerine ulaşmasının ardından önemli bir değişime uğramadığı gözlenmiştir. Bu durum, bulamaç çamuru konsolidasyon yöntemi ile hazırlanan numunelerin normal konsolide özellikte olduğunu doğrular niteliktedir. Şekil 4.a'da başlangıç kayma gerilmesinin olmadığı durumda $\left(\tau_{\varsigma} / \mathrm{p}^{\prime}=0\right)$, yenilme anındaki aşırı boşluk suyu basıncı $109.0 \mathrm{kPa}$ iken, $\tau_{s} / \mathrm{p}^{\prime}=0.15,0.30$ ve 0.45 gerilme koşulları için yenilme anındaki boşluk suyu basınçlarının $\left(\Delta \mathrm{u}_{\mathrm{f}}\right)$, sırasıyla 91.1, 48.2 ve $21.4 \mathrm{kPa}$ seviyelerine düştüğü görülmektedir. Benzer şekilde, $\mathrm{p}^{\prime}=400$ $\mathrm{kPa}$ 'lık gerilme altındaki numuneler için de izotropik gerilme şartları altındaki numune için $\Delta \mathrm{u}_{\mathrm{f}}=238.3 \mathrm{kPa}$ iken, başlangıç kayma gerilmesi seviyelerindeki artış ile bu değerlerin sırasıyla 191.8, 91.0 ve $35.8 \mathrm{kPa}$ seviyelerine düştüğü görülmektedir. Bu durum, yapı yükleri altında konsolidasyonunu tamamlamış olan normal konsolide killerde, ilave yükler sonrasında oluşacak olan boşluk suyu basıncı artışının sınırlı kalacağı bilgisini vermektedir. Benzer değerlendirmeler, başlangıç kayma gerilmesine maruz kumlu ve killi zeminlerin tekrarlı yükler altındaki boşluk suyu basıncı oluşumu için de birçok araştırmacı tarafından gözlenmiştir $[9,11]$.
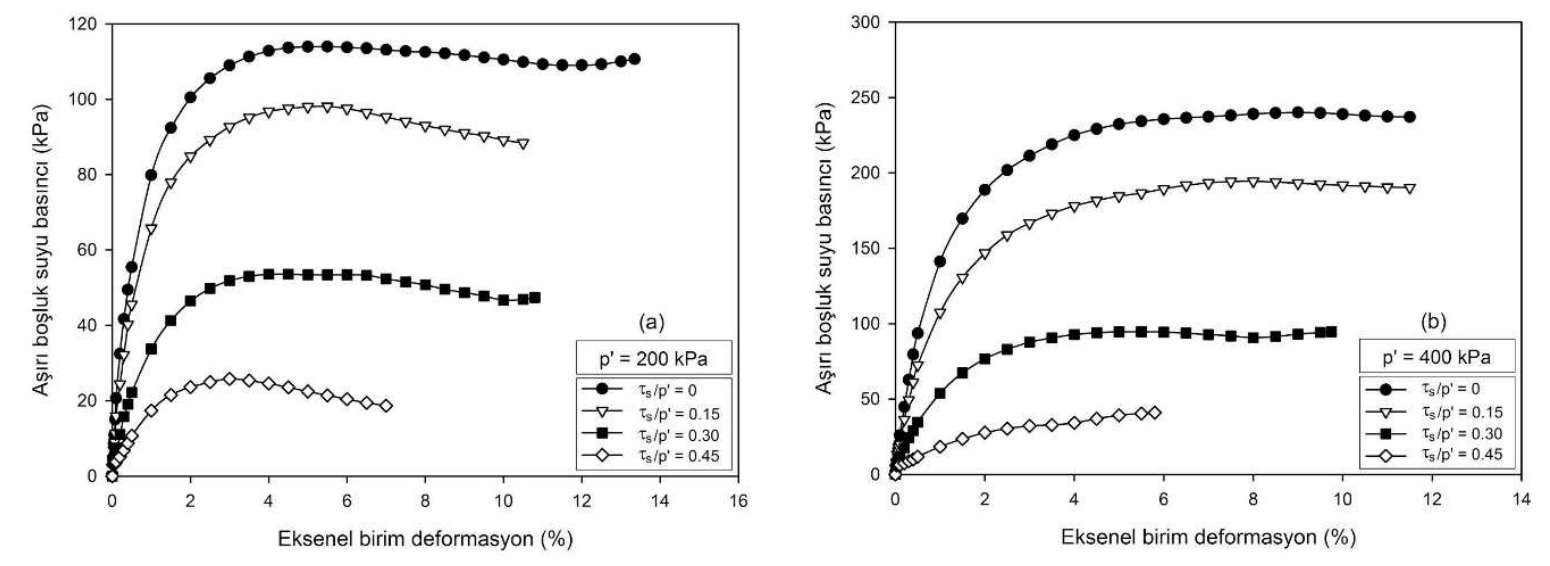

Şekil 4. a) p' $=200 \mathrm{kPa}, \mathrm{b}) \mathrm{p}^{\prime}=400 \mathrm{kPa}$ için aşırı boşluk suyu basıncı oluşumu

\section{Gerilme İzleri ve Yenilme Zarfi}

Ortalama efektif gerilmesi, $\mathrm{p}^{\prime}=200$ ve $400 \mathrm{kPa}$ olan ve başlangıç kayma gerilmesine maruz bırakılmıs olan numunelerin gerilme izleri Şekil 5'de verilmiştir. Numunelerin drenajlı şartlarda ön-kesmeye maruz bırakıldığı bölümde, gerilme izi 3/1'lik eğimle artarak hedeflenen başlangıç gerilme durumuna ulaşmaktadır. Bu noktadan sonra numuneler, drenajsız kesmeye maruz bırakıldıklarında, başlangıç kayma gerilmesi oranı, $\tau_{\varsigma} / \mathrm{p}^{\prime}=0$ ve 0.15 olan numunelerin birbirlerine oldukça yakın noktalarda yenilme zarfına ulaştıkları görülmektedir. Buna karşın, başlangıç kayma gerilmesi oranının, 0.30 ve 0.45 olduğu deneylerde ise boşluk suyu basıncındaki artışın sınırlı oluşu ve yenilme anındaki deviatör gerilme seviyesi nedeniyle izotropik durumdaki numunelere kıyasla daha üst noktalarda yenilme zarfına ulaşmakta ve yenilme daha hızlı gerçekleşmektedir. $\mathrm{p}^{\prime}=200 \mathrm{kPa}{ }^{\prime}$ lık ortalama efektif gerilme ve başlangıç kayma gerilmesi oranı, $\tau_{s} / p^{\prime}=0.60$ olan CAU-04 no.lu deney numunesinde ise henüz 
drenajlı ön-kesme aşamasındayken aşırı deformasyon sonucunda yenilme gerçekleşmiştir. Bu numunenin gerilme izi incelendiğinde, aşırı deformasyonlar sonucunda yenilmenin gerçekleştiği anda, gerilme izinin de yenilme zarfına ulaştığı tespit edilmiştir. Şekil 5 incelendiğinde, genel bir eğilim olarak, izotropik numune sonuçlarından elde edilen yenilme zarfının başlangıç kayma gerilmesine maruz zeminlerin de yenilme davranışını temsil eder nitelikte olduğu söylenebilecektir. Bu durum, yenilme zarfı tanımının başlangıç kayma gerilmesinden etkilenmediğini ortaya koymaktadır. Benzer davranış Hyodo vd. [7] ve Nishie vd. [27] tarafından da gözlenmiş olup, araştırmacılar anizotropik ve izotropik olarak konsolide edilen killerin kritik durum çizgilerinin aynı olduğunu vurgulanmıştır. Nishie vd. [27] bu davranışı, kritik durum çizgisinin gerilme kaynaklı anizotropiden etkilenmediği ve kilin doğal özelliği olduğu şeklinde yorumlamışlardır.

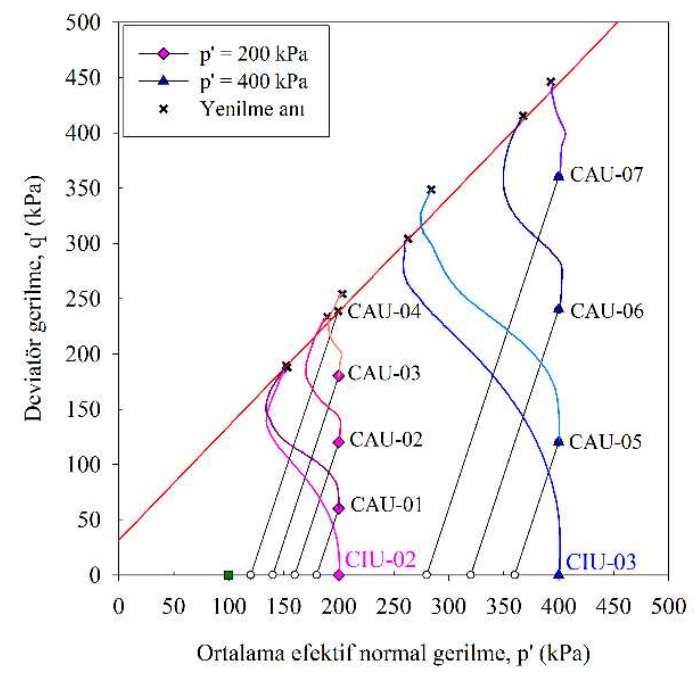

Şekil 5. p' = 200 ve $400 \mathrm{kPa}$ olan numuneler için gerilme izleri

\section{DENEY BULGULARININ DEĞERLENDİIILMESİ}

Çalışma kapsamında gerçekleştirilen deney sonuçlarından, başlangıç kayma gerilmesinin varlığının, normal konsolide kaolin kilinin yenilme anındaki maksimum deviatör gerilme $\left(\sigma_{\mathrm{d}, \max }\right)$ değerinde önemli ölçüde azalmalara neden olabileceği Şekil 3'den anlaşılmaktadır. Bu azalım etkinin ölçüsünü daha net bir şekilde ortaya koyabilmek için, bu çalışmadan elde edilen sonuçlara ilave olarak Hyodo vd. [7] ve Yasuhara vd. [24]'nin bulgularının da eklendiği Şekil 6 oluşturulmuştur. Şekil 6' da x ekseni, başlangıç kayma gerilmesinin $\left(\tau_{\mathrm{s}}\right)$, izotropik olarak konsolide edilen numunelerin drenajsız kesme sırasındaki kayma mukavemeti $\left(\mathrm{s}_{u, i z o}\right)$ ile normalize edilmiş değerleri $\left(\tau_{\mathrm{s}} / \mathrm{s}_{\mathrm{u}, \mathrm{izo}}\right)$ şekilde düzenlenmiştir. $\mathrm{Bu}$ ifade, anizotropik gerilme koşullarındaki numunelerin maruz durumda oldukları başlangıç kayma gerilmelerinin, izotropik gerilme koşullarındaki drenajsız kayma mukavemetine kıyasla seviyesini göstermektedir. Ancak, başlangıç kayma gerilmesinin uygulanması sırasında drenaja izin verildiği için $\left(\tau_{\mathrm{s}} / \mathrm{s}_{\mathrm{u}, \text { izo }}\right)$ ifadesi 1 'den daha büyük değerler alabilecektir. Örneğin, bu çalışmada, 400 kPa'lık izotropik çevre gerilmesi altında konsolide edilen CIU-03 numunesinin drenajsız kayma mukavemeti, $s_{\mathrm{u}}$ $=\sigma_{\mathrm{d}, \max } / 2=152 \mathrm{kPa}$ iken, aynı ortalama efektif gerilme altındaki CAU-07 numunesine drenajlı şartlarda yenilme olmaksızın 180 kPa'lık başlangıç kayma gerilmesi uygulanabilmiştir. Şekil 6'daki grafiğin y ekseni ise, başlangıç kayma gerilmesine maruz numunelerin drenajsız kesme sırasındaki kayma mukavemetlerinin ( $\mathrm{s}_{\mathrm{u}, \text { anizo }}$ ), aynı gerilme seviyesindeki izotropik olarak konsolide edilen numunenin kayma mukavemetine $\left(\mathrm{s}_{\mathrm{u}, \mathrm{izo}}\right.$ ) oranı olarak verilmiştir. Böylece, başlangıç kayma gerilmesinin zemin numunelerinin drenajsız koşullardaki kayma mukavemetine olan etkisi genelleştirilmeye çalışılacaktır.

Şekil 6'da kullanılan veriler, Hyodo vd. [7] ve Yasuhara vd. [24]'nin çalışmalarındaki verilerle birlikte plastisite indisleri, PI = $17-73$ aralığında, ortalama efektif gerilme değerleri ise $\mathrm{p}^{\prime}=200$ ve $400 \mathrm{kPa}$ olan deney sonuçlarını içermektedir. Şekil 6 incelendiğinde, bu çalışmadan elde edilen bulgular ile literatürdeki çalışma 
sonuçlarının [7, 24] uyum içerisinde olduğu görülmektedir. Numunelerin plastisite indisleri ve ortalama efektif gerilmelerinin geniş bir aralıkta olmasına rağmen, verilerin bir bant içerisinde kaldığı görülmektedir. Bu grafik üzerinde, verileri temsil edecek şekilde önerilen regresyon denklemi siyah düz çizgi ile gösterilmiştir. Önerilen regresyon denklemi için \%95 güven aralığı çizildiğinde, verilerin oldukça önemli bir bölümünün bu bant içerisine düştüğü görülmektedir. $\mathrm{Bu}$ aşamada oluşturulacak bir regresyon denklemi için henüz drenajlı ön-kesme aşamasında iken yenilmenin gerçekleştiği CAU-04 deney numunesinin önemli bir bilgi içerdiği anlaşılmaktadır. $\mathrm{Bu}$ numunede, anizotropik konsolidasyon sonrasında bir drenajsız kesme aşaması uygulanamadığından, bu numunenin drenajsız kayma mukavemeti $\mathrm{s}_{\mathrm{u}, \text { anizo }}=0$ olarak değerlendirilebilir. Bu nedenle, hangi gerilme koşulları altında olursa olsun, başlangıç kayma gerilmesinin belli bir değeri için $\mathrm{s}_{\mathrm{u} \text {,anizo }} / \mathrm{s}_{\mathrm{u}, \text { izo }}$ değerinin 0 olacağ bir durum mutlaka gerçekleşecektir ve eğri belirli bir değerde x eksenini kesecektir.

Şekil 6'dan görüleceği üzere, başlangıç kayma gerilmesi arttıkça, normalize edilmiş drenajsız kayma mukavemeti $\left(\mathrm{s}_{\mathrm{u}, \text { anizo }} / \mathrm{s}_{\mathrm{u}, \text { izo }}\right.$ ) oldukça hızlı bir düşüş eğilimi göstermektedir. Bu gözlem, izotropik olarak konsolide edilen numunelerden elde edilen drenajsız kayma mukavemetinin, başlangıç kayma gerilmesinin var olduğu arazi koşullarındaki zeminler için kullanımının doğru olmayacağını göstermektedir. Bu problemi ortadan kaldırabilmek için Seed [28]'in başlangıç statik kayma gerilmesinin kumların sıvılaşma direnci üzerindeki etkisini yansıtmak için önerdiği $\mathrm{K}_{\alpha}$ düzeltme faktörüne benzer formda bir düzeltme faktörünün tanımlanmasına ihtiyaç duyulmaktadır. Bu amaç doğrultusunda, izotropik olarak konsolide edilmiş $\left(\sigma_{3 c}{ }^{\prime}=p^{\prime}\right)$ numunelerin drenajsız kayma mukavemeti $\left(\mathrm{s}_{\mathrm{u}, \text { izo }}\right)$ değerlerinden, aynı ortalama efektif gerilmeli ve başlangıç kayma gerilmesine maruz zemin elemanlarının drenajsız kayma mukavemetleri ( $\mathrm{s}_{\mathrm{u}, \text { anizo }}$ ) Denklem 3'de önerilen ifade ile tahmin edilebilecektir.

$$
s_{u, \text { anizo }}=K_{s} . s_{u, i z o}
$$

Burada, $\mathrm{K}_{\mathrm{s}}$ monotonik yükleme koşulları için başlangıç kayma gerilmesi düzeltme faktörü olup, Şekil 6'daki sınırlı sayıdaki verilere dayalı olarak gerçekleştirilen regresyon analizinden elde edilerek, Denklem 4'de tanımlanmıştır. Ancak, bu çalışma kapsamında kullanılan verilerin sayısı itibariyle, bu ifadenin genel bir davranış tespiti olarak değerlendirilmesi daha uygun olacaktır. Benzer nitelikteki çalışmaların artırılması ve veri sayısındaki artış ile önerilen bu düzeltme faktörünün istatistiksel olarak daha anlamlı bir regresyon denklemi haline dönüştürülebilmesi mümkün gözükmektedir.

$$
K_{s}=-0.8617\left(\frac{\tau_{s}}{s_{u, i z o}}\right)^{3}+1.5877\left(\frac{\tau_{s}}{s_{u, i z o}}\right)^{2}-1.3348\left(\frac{\tau_{s}}{s_{u, i z o}}\right)+1.00
$$

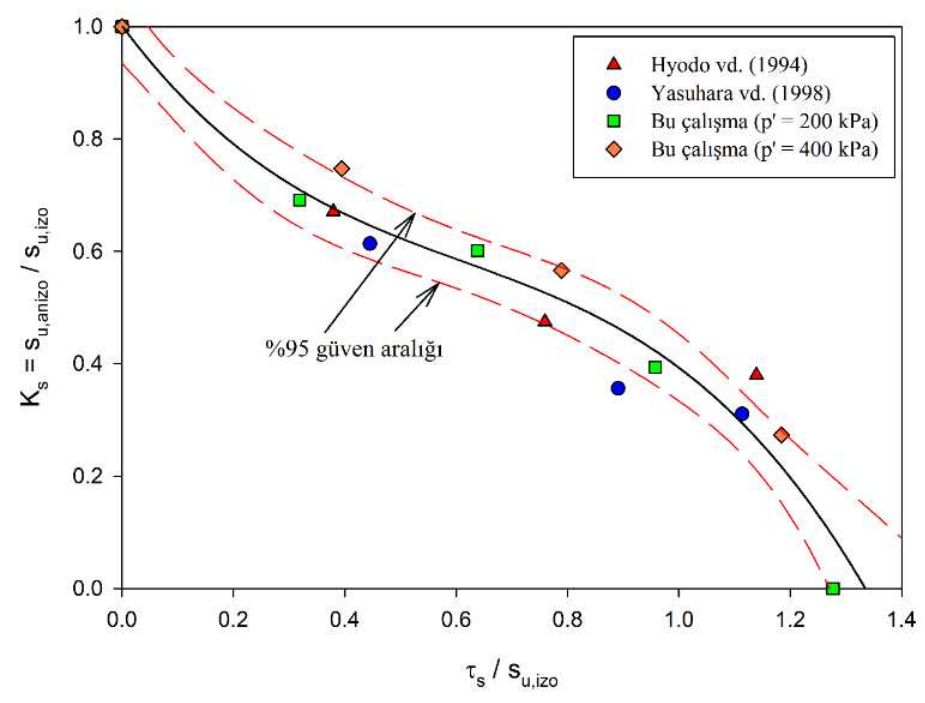

Şekil 6. Başlangıç kayma gerilmesi varlığının drenajsız kayma mukavemetine etkisi 
Kesme aşamasında aşırı boşluk suyu basıncı oluşum davranışını değerlendirmek için, yenilme anındaki boşluk suyu basıncı değerleri, konsolidasyon sonrası efektif çevre gerilmeleri $\left(\sigma_{3 c}{ }^{\prime}\right)$ ile normalize edilerek, boşluk suyu basıncı üzerindeki çevre gerilmesi etkisi devre dışı bırakılmaya çalışılmıştır. Şekil 4'deki deney bulgularına göre, yenilme anındaki normalize edilmiş aşırı boşluk suyu basıncının $\left(\Delta \mathrm{u}_{\mathrm{f}} / \sigma_{3 c}{ }^{\prime}\right)$, başlangıç kayma gerilmesi oranı ile değişimi Şekil 7'de sunulmuştur. Başlangıç kayma gerilmesi oranının yaklaşık olarak 0.10'dan küçük olduğu durumlarda, başlangıç kayma gerilmesinin kaolin kilinin boşluk suyu basıncı davranışını çok fazla etkilemediği görülmektedir. Bu gözlem, düşük kayma gerilmesi seviyelerindeki numunelerin gerilme izlerinin, izotropik durumdaki numunelerinkine benzer oluş nedenini de açıklamaktadır. Başlangıç kayma gerilmesi oranının artmasıyla beraber, normalize edilmiş boşluk suyu basıncında önemli azalmalar meydana gelmektedir. Her iki ortalama efektif gerilme seviyesi için de, normalize edilmiş boşluk suyu basıncının birbirine oldukça yakın olduğu görülmektedir. Bu durum, kesme aşamasında oluşacak olan normalize edilmiş boşluk suyu basıncının, ortalama efektif normal gerilmeden ziyade başlangıç kayma gerilmesinin büyüklüğünden daha çok etkilenebileceği algısını oluşturmaktadır. Yine, konuyla ilgili verilerin artması ile beraber bu davranışı daha net olarak ortaya koyulabilecek ve aşırı boşluk suyu basıncı oluşumu üzerinde başlangıç kayma gerilmelerinin etkisini yansıtmak üzere regresyon denklemleri ilerleyen çalışmalarda önerilebilecektir.

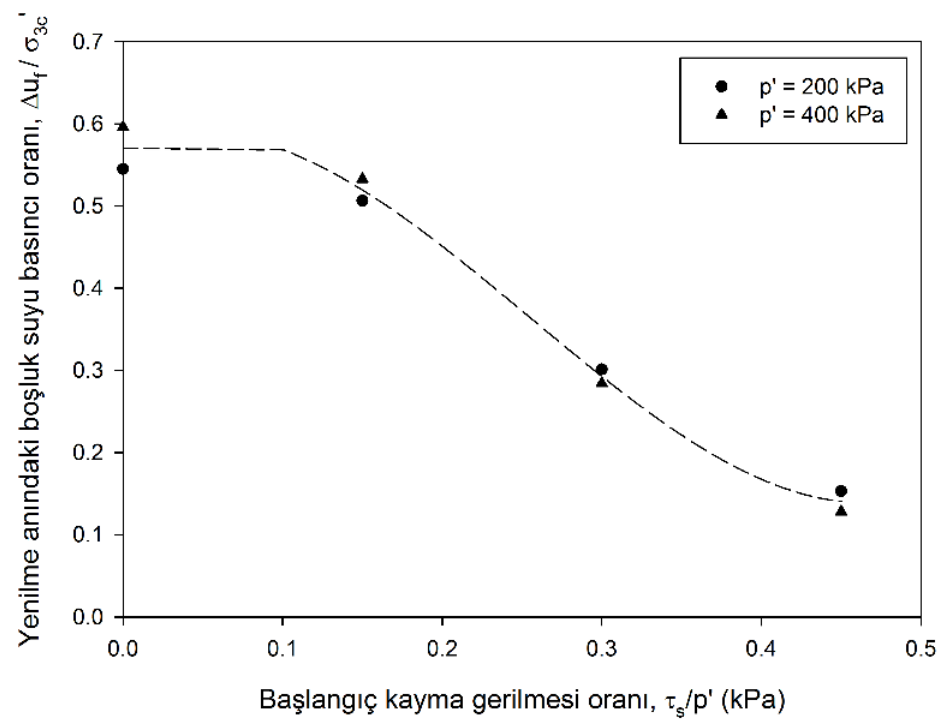

Şekil 7. Başlangıç kayma gerilmesi oranının normalize edilmiş boşluk suyu basıncına etkisi

\section{SONUÇLAR}

Gerçek arazi koşullarındaki zemin tabakalarının genellikle başlangıç kayma gerilmesine maruz olmasına rağmen, maliyet, zaman ve kolaylık gibi faktörler, laboratuvarlarda üç eksenli basınç deneylerinin izotropik gerilme şartlarında yapılmasına neden olmaktadır. Bu çalışmada oluşturulan sistematik bir deney programından elde edilen deneysel bulgulara dayalı olarak aşağıdaki sonuçlara ulaşılmıştır:

- Aynı ortalama efektif gerilme seviyesindeki zeminler için, başlangıç kayma gerilmesindeki artış, kaolin kilinin maksimum deviatör gerilme değerinde önemli miktarlarda azalışa neden olabilmektedir. Maksimum deviatör gerilmede gözlemlenen bu azalımlar, $\tau_{s} / \mathrm{p}^{\prime}=0.15$ olan numunelerde $\% 25-31, \tau_{s} / \mathrm{p}^{\prime}=0.30$ olan numunelerde $\% 40-43, \tau_{s} / \mathrm{p}^{\prime}=0.45$ olan numunelerde ise \%60-73 aralığına kadar ulaşabilmektedir. Bu durum, izotropik olarak konsolide edilen numunelerden elde edilen kayma dayanımının, arazideki başlangıç kayma gerilmesine maruz killerin gerilme şartlarını değerlendirmede emniyetsiz tarafta kalınacağı anlamına gelmektedir. İzotropik konsolidasyon sonrasında elde edilen drenajsız kayma mukavemetinin, anizotropik numuneler için kullanımını sağlayabilmek için başlangıç kayma gerilmesinin fonksiyonu olan bir düzeltme faktörü $\left(\mathrm{K}_{\mathrm{s}}\right)$ önerilmiștir. 
- Başlangıç kayma gerilmesi oranının $\left(\tau_{\mathrm{s}} / \mathrm{p}^{\prime}\right)$ yaklaşık olarak 0.10' dan küçük olduğu durumlarda, boşluk suyu basıncı oluşumunun başlangıç kayma gerilmesinden önemli miktarda etkilenmediği, ancak bu oranının artmasıyla beraber yenilme anındaki normalize edilmiş aşırı boşluk suyu basıncının $\left(\Delta \mathrm{u}_{\mathrm{f}} / \sigma_{\mathrm{c}}{ }^{\prime}\right)$ yaklaşık $\% 75$ civarına kadar azalabileceği tespit edilmiştir.

- İzotropik gerilme şartlarındaki deney sonuçlarına dayalı olarak elde edilen yenilme zarfının, başlangıç kayma gerilmesine maruz numuneler için de geçerli olduğu gözlenmiştir. Bu gözlem, yenilme zarfının anizotropiden / başlangıç kayma gerilmesi seviyesinden etkilenmediğini göstermektedir. Ayrıca, başlangıç kayma gerilmesinin artmasıyla beraber, maksimum deviatör gerilme ve aşırı boşluk suyu basıncındaki azalıştan dolayı, numunelerin yenilme zarfına çok daha hızlı ulaştıkları belirlenmiştir.

- Konsolidasyon sonrasındaki boşluk oranını sabit tutabilmek için hazırlanan deney programı seçimi sonunda, konsolidasyon sonundaki boşluk oranının ortalama efektif gerilme (p') tarafından kontrol edildiği gözlenmiştir.

Bu çalışma kapsamında normal konsolide kaolin kilinin, izotropik şartlarda gerçekleştirilen monotonik üç eksenli basınç deneylerinden elde edilen drenajsız kayma mukavemetlerinin, anizotropik şartlardakinden daha büyük değerler aldığı görülmüştür. Benzer bir davranışın; başlangıç kayma gerilmesine maruz killerin tekrarlı yükler altındaki davranışında da görülebileceği düşüncesi araştırmaya değer bir konudur. Böyle bir durumda, özellikle, yapı yükleri altındaki killi zeminlerin dinamik yükler altındaki kayma direnci ile serbest saha koşullarındaki $\left(\tau_{\mathrm{s}}=0\right)$ killerin kayma direnci arasındaki ilişkinin incelenmesi ilerleyen çalışmalar için önerilebilir.

\section{KAYNAKLAR}

[1] Yoshimi, Y., \& Oh-Oka, H. (1975). Influence of degree of shear stress reversal on the liquefaction potential of saturated sand. Soils and Foundations, 15(3), 27-40.

[2] Yang, Z.X., \& Pan, K. (2017). Flow deformation and cyclic resistance of saturated loose sand considering initial static shear effect. Soil Dynamics and Earthquake Engineering, 92, 68-78.

[3] Dong, W., Hu, X., Zhang, Y., \& Fu, H. (2019). Dynamic characteristics of marine soft clay under variable phase difference and initial static shear stress. Marine Georesources \& Geotechnology, DOI: 10.1080/1064119X.2019.1622159

[4] Wei, X., \& Yang, J. (2019). Cyclic behavior and liquefaction resistance of silty sands with presence of initial static shear stress. Soil Dynamics and Earthquake Engineering, 122, 274-289.

[5] Hyodo, M., Tanimizu, H., Yasufuku, N., \& Murata, H. (1994a). Undrained cyclic and monotonic triaxial behavior of saturated loose sand. Soils and Foundations, 34(1), 19-32.

[6] Zhang, J., Cao, J., \& Huang, S. (2019). Experimental study on the effects of initial shear stress and vibration frequency on dynamic strength of saturated sands. Advances in Materials Science and Engineering, Article ID: $3758527,1-9$.

[7] Hyodo, M., Yamamoto, Y., \& Sugiyama, M. (1994b). Undrained cyclic shear behaviour of normally consolidated clay subjected to initial static shear stress. Soils and Foundations, 34(4), 1-11.

[8] Boulanger, R.W., \& Idriss, I.M. (2007). Evaluation of cyclic softening in silts and clays. Journal of Geotechnical and Geoenvironmental Engineering, 133(6), 641-652.

[9] Wang, J., Cai, Y., \& Yang, F. (2013). Effects of initial shear stress on cyclic behavior of saturated soft clay. Marine Georesources \& Geotechnology, 31(1), 86-106.

[10] Mayne, P.W. (1985). Stress anisotropy effects on clay strength. Journal of Geotechnical Engineering, 111(3), $356-366$. 
[11] Stipho, A.S. (1989). Effect of stress rotation on the strength and deformation of laboratory prepared clay samples. Journal of King Saud University - Engineering Sciences, 1(1-2), 67-81.

[12] Yasuhara, K., Yamanouchi, T., \& Hirao, K. (1982). Cyclic strength and deformation of normally consolidated clay. Soils and Foundations, 22(3), 77-91.

[13] Konrad, J.M., \& Wagg, B.T. (1993). Undrained cyclic loading of anisotropically consolidated clayey silts. Journal of Geotechnical Engineering, 119(5), 929-947.

[14] Bhuria, N.R., \& Sachan, A. (2014). Shear strength and constant rate of strain consolidation behaviour of cement-treated slurry-consolidated soft soil. Current Science, 106(7), 972-979.

[15] Cai, Y., Hao, B., Gu, C., Wang, J., \& Pan, L. (2018). Effect of anisotropic consolidation stress paths on the undrained shear behavior of reconstituted Wenzhou clay. Engineering Geology, 242, 23-33.

[16] Pandya, S., \& Sachan, A. (2019). Experimental studies on effect of load repetition on dynamic characteristics of saturated Ahmedabad cohesive soil. International Journal of Civil Engineering, 17(6), 781-792.

[17] Pradhan, T.B.S., \& Ueno, Y. (1998). Cyclic deformation characteristics of clay under different consolidation histories. Pre-failure Deformation Behaviour of Geomaterials, Geotechnique, Thomas Telford Ltd., London, 329-335.

[18] Hyde, A.F.L, Higuchi, T., \& Yasuhara, K. (2006). Liquefaction, cyclic mobility, and failure of silt. Journal of Geotechnical and Geoenvironmental Engineering, 132(6), 716-735.

[19] Germaine, J.T., \& Ladd, C.C. (1988). Triaxial testing of saturated cohesive soils. Advanced Triaxial Testing of Soil and Rock, ASTM STP977, ASTM, Philadelphia, 421-459.

[20] Head, K.H. (1994). Manual of Soil Laboratory Testing - Volume 2: Permeability, Shear Strength and Compressibility Tests. John Wiley \& Sons, Inc., New York, p. 440.

[21] Wang, Y.H., \& Siu, W.K. (2006). Structure characteristics and mechanical properties of kaolinite soils. II. Effects of structure on mechanical properties. Canadian Geotechnical Journal, 43(6), 601-617.

[22] Sachan, A., \& Penumadu, D. (2007). Effect of microfabric on shear behavior of kaolin clay. Journal of Geotechnical and Geoenvironmental Engineering, 133(3), 306-318.

[23] ASTM D-4767-11. (2011). Standard test method for consolidated undrained triaxial compression test for cohesive soils. ASTM International, p.14.

[24] Yasuhara, K., Hyde, A.F.L., Toyota, N., \& Murakamı, S. (1998). Cyclic stiffness of plastic silt with an initial drained shear stress. Pre-failure Deformation Behaviour of Geomaterials, Thomas Telford Ltd., London, 373-382.

[25] Hyodo, M., Hyde, A.F.L., Yamamoto, Y., \& Fujii, T. (1999). Cyclic shear strength of undisturbed and remoulded marine clays. Soils and Foundations, 39(2), 45-58.

[26] Hyde, A.F.L, Higuchi, T., \& Yasuhara, K. (2007). Postcyclic recompression, stiffness, and consolidated cyclic strength of silt. Journal of Geotechnical and Geoenvironmental Engineering, 133(4), 416-423.

[27] Nishie, S., Wang, L. \& Seko, I. (2006). Undrained Shear Behaviors of High Plastic Normally $\mathrm{K}_{0^{-}}$ Consolidated Marine Clays. Soil Stress-Strain Behavior: Measurement, Modeling and Analysis Geotechnical Symposium in Roma, 273-286.

[28] Seed, H.B. (1983). Earthquake Resistant Design of Earth Dams. Proc. Symp. on Seismic Design of Embankments and Caverns, ASCE, 1, 41-64. 